\title{
A Functional Outcome Prediction Model of Acute Traumatic Spinal Cord Injury Based on Extreme Gradient Boost
}

\section{Sizheng Zhan}

Peking University People's Hospital

\section{Boxuan Huang}

Peking University People's Hospital

\section{Wenyong Xie}

Peking University People's Hospital

Feng Xue ( $\nabla$ pku_xf@163.com)

Peking University People's Hospital https://orcid.org/0000-0001-9852-2963

\section{Dianying Zhang}

Peking University People's Hospital

\section{Baoguo Jiang}

Peking University People's Hospital

\section{Research Article}

Keywords: acute spinal cord injury, prediction model, Extreme Gradient Boost, Spinal Cord Independence Measure

Posted Date: September 28th, 2021

DOl: https://doi.org/10.21203/rs.3.rs-905273/v1

License: (c) (i) This work is licensed under a Creative Commons Attribution 4.0 International License. Read Full License 


\section{Abstract}

Purpose: We aimed to construct a nonlinear regression model through Extreme Gradient Boost (XGBoost) to predict functional outcome 1 year after surgical decompression for patients with acute spinal cord injury (SCl).

Methods: We prospectively enrolled 249 patients with acute SCI from 5 primary orthopedic centers from June 1, 2016, to June 1, 2020. We identified a total of 6 predictors with three aspects: 1) clinical characteristics, including age, American Spinal Injury Association (ASIA) Impairment Scale (AIS) at admission, level of injury and baseline ASIA motor score (AMS); 2) MR imaging, mainly including Brain and Spinal Injury Center (BASIC) score; 3 ) surgical timing, specifically comparing whether surgical decompression was received within 24 hours or not. We assessed the SCIM score at 1 year after the operation as the functional outcome index. XGBoost was used to build a nonlinear regression prediction model through the method of boosting integrated learning.

Results: We successfully constructed a nonlinear regression prediction model through XGBoost and verified the credibility. The average absolute value of the difference between the predicted value and the actual value is 3.72 ( $t=1.29, P=0.203)$, ranging from 0 to 8.44 . AMS and age ranked first and second in predicting the functional outcome.

Conclusion: We verified the feasibility of using XGBoost to construct a nonlinear regression prediction model for the functional outcome of patients with acute SCl, and we found that age and AMS play the most important role in predicting the functional outcome.

Trial registration: ClinicalTrials.gov identifier: NCT03103516.

\section{Introduction}

Acute traumatic spinal cord injury (SCl) is a severe condition that affects individuals worldwide and is associated with a high rate of disability ${ }^{[9,12,13]}$. Acute $\mathrm{SCl}$ not only greatly aggravates the economic burden of society, family, and individuals but also exerts great psychological pressure on patients and their families ${ }^{[20,24]}$. Prognosticating functional outcome after acute $\mathrm{SCl}$ is important to guide management strategies and to give the patients and their families a realistic idea of long-term expectations ${ }^{[11,27]}$.

In 2012, Wilson and colleagues ${ }^{[27]}$ retrospectively analyzed the clinical and imaging features of patients with acute $\mathrm{SCl}$, used the functional independence measure (FIM) as a functional outcome indicator, and successfully constructed a linear regression model to predict FIM in patients after 1 year. In 2017, Kaminski and colleagues ${ }^{[11]}$ prospectively analyzed the acute phase clinical characteristics of patients with acute $\mathrm{SCl}$, used the Spinal Cord Independence Measure (SCIM) as a functional prognostic indicator, and constructed a linear regression model to predict SCIM in patients after 1 year. However, the prognostic relationship between functional outcome and different indicators is often not a simple linear 
correlation. At the same time, the in-depth research on SCI treatments, such as methylprednisolone ${ }^{[2,6]}$ and early surgery ${ }^{[1,4,5,22,28]}$, has indicated that these measures have a significant impact on the prognosis of patients with acute $\mathrm{SCl}$.

Extreme Gradient Boost (XGBoost) is an open source machine learning project developed by Chen Tianqi et al. ${ }^{[30]}$ in 2016, and it exhibited the most advanced performance in the Kaggle machine learning competition. XGBoost was developed on the basis of Gradient Boosting Decision Tree (GBDT) and is a type of boosting ensemble learning. Ensemble learning refers to the construction of multiple classifiers, such as Classification and Regression Tree (CART), to predict the dataset and then use a certain strategy to integrate results of the multiple classifiers as the final prediction result. As a common method of boosting ensemble learning, every calculation of GBDT is to reduce the last residual and then establishes a new model in the direction of residual reduction (negative gradient). XGBoost is faster and more efficient than GBDT, so it is called X (Extreme) GBoost. Ensemble learning has been widely used in many fields, such as industry, commerce and environmental protection ${ }^{[14,23]}$.

Here, through a designed prospective cohort study, we included three aspects of potential predictors (clinical features, MR imaging and surgical timing), chose SCIM as the functional outcome indicator, and aimed to construct a nonlinear regression model through XGBoost to predict patient functional outcome 1 year after surgical decompression.

\section{Methods}

\section{Study cohort}

We conducted a prospective, multicenter nonrandomized controlled trial involving five hospitals in Beijing: 1) Peking University People's Hospital, 2) Peking University Third Hospital, 3) Beijing Friendship Hospital Affiliated to Capital Medical University, 4) Chaoyang Hospital Affiliated to Capital Medical University, and 5) Chinese People's Liberation Army (PLA) General Hospital. All the hospitals recorded patient information in a database specifically created for $\mathrm{SCl}$ cases. Prior to the start of the study, the protocol involving all five hospitals was approved by the ethics committee. Methylprednisolone was administered at the discretion of the treating team according to the recommendations of the NASCIS-2 study ${ }^{[2]}$.

Inclusion criteria

1. Age: $16-85$ years old, irrespective of sex;

2. Final diagnosis by spine magnetic resonance (MR) imaging;

3. Cervical and thoracic fracture dislocation or without fracture dislocation but combined with spinal cord injury;

4. No other injury involving life, injury severity score < $16^{[25]}$;

5. Receiving surgical decompression 
1. History of mental illness and metal allergy;

2. Long-term alcohol abuse and drug abuse;

3. Did not agree to participate in this trial/the legal representative of the patient refuses to sign informed consent;

4. Poor compliance, could not be followed up as required

A total of 249 patients met all inclusion criteria and were included in the study from June 1, 2016, to June 1, 2020. At the same time, we retrospectively included patients with acute SCl at Tianjin Binhai Hospital from June 1,2016 , to June 1, 2020, as the validation sample set. The inclusion and exclusion criteria and data collection were consistent with the prospective study.

\section{Predictor variables}

The determination of our predictor variables were based on four main principles: 1) the literature proves that the selected variables are related to the patient's functional outcome; 2) the selected variables are easy to obtain in clinical work; 3 ) the selected variables have good reliability among doctors; 4) the selected variables cover the three aspects including patient's clinical characteristics, MR imaging and treatment plan. Based on these four principles, we identified a total of 6 predictors with three aspects: 1) clinical characteristics, including age, American Spinal Injury Association (ASIA) Impairment Scale (AIS) at admission, level of injury and baseline ASIA motor

score (AMS); 2) MR imaging, mainly including Brain and Spinal Injury Center (BASIC) score; 3) surgical timing, specifically comparing whether surgical decompression was received within 24 hours or not (Table 1A). All six predictors have demonstrated prognostic significance in relation to long-term functional outcome after $\mathrm{SCI}^{[1,4,5,7,11,15,21,22,27,28]}$. A professional orthopedic surgeon conducted physical examinations to identify the patients' neurologic level of injury, AMS and AIS at admission. MR imaging was the earliest recorded MR result for patients. The MR imaging examinations were performed with a 1.5-Tesla MR scanner (Signa CV/I, GE Healthcare, Milwaukee, WI). We assessed sagittal T2 FSE, sagittal T1, and axial T2 FSE sequences to calculate the BASIC score. Two authors individually and independently assessed the imaging data twice to eliminate intra- and inter-observer bias. The timing of the operation was to truthfully record the time between injury and the operation.

\section{Outcome and follow-up}

We assessed the SCIM score at 1 year after the operation as the functional outcome index. The SCIM score is composed of 19 items, with three main domains (Table 1B): self-care (six items, scores range from 0-20); respiration and sphincter management (four items, scores range from 0-40); and mobility (nine items, scores range from 0-40). The SCIM score was first proposed by Cate et al. in $1997^{[3]}$ and has 
now been revised in a third edition ${ }^{[19]}$. An international multicenter study found that SCIM has good reliability, validity and practicability in people with $\mathrm{SCI}^{[8]}$ and is superior to $\mathrm{FIM}^{[16]}$.

\section{Statistical analysis}

XGBoost builds a nonlinear regression prediction model through the method of boosting integrated learning. Compared with other boosting ensemble learning, XGBoost can be used to construct predictive models more efficiently and accurately by performing second-order Taylor expansion, regularization term, and optimizing greedy algorithms on the objective function. We implemented XGBoost through Python 3.9. Since our sample data are relatively small, we choose $n$ _estimators $=10000$ (CART) in the XGBoost prediction model. A paired-sample T test was used to test the accuracy of the prediction set by IBM SPSS Statistics for Windows, version 26.0 (IBMCorp., Armonk, N.Y., USA).

\section{Results}

\section{Study population}

A total of 249 patients with acute $\mathrm{SCl}$ were included in our prospective study. The characteristics of the population are summarized in Table 2. The average age of the patients was 50.45 years, most of them were male, and the main injury was to the cervical segment. D-grade patients accounted for nearly half of the number, and there were 59 A-grade patients. Approximately one-third of patients received surgical decompression within 24 hours. In the retrospective validation sample set, a total of 48 patients were included in the study, and the population characteristics are summarized in Supplementary Material 1.

\section{Modeling and validation}

XGBoost was used to build the nonlinear predictive model, and the coding data are shown in Supplementary Material 2. The first 10 CARTs are shown in Supplementary Material 3.

The nonlinear regression prediction model is saved in Supplementary Material 4. The validation sample set was used to verify the regression prediction model, and the results are shown in Figure $1(t=1.29$, $\mathrm{P}=0.203)$. The average absolute value of the difference between the predicted value and the actual value is 3.72 , ranging from 0 to 8.44 .

\section{Other findings}

Moreover, we ranked the importance of features in constructing predictive models (Figure 2). We found that AMS and age played the most important roles in constructing predictive models. The correlation between the 6 predictors is shown in Figure 3. There is an obvious correlation between AIS, AMS and BASIC score.

\section{Discussion}


We prospectively enrolled 249 patients with acute SCI from 5 primary orthopedic centers. Based on 6 predictors with three aspects (age, AIS at admission, baseline AMS, level of injury, BASIC score and surgical timing), we successfully constructed a nonlinear regression prediction model through XGBoost and verified the credibility.

Acute SCI has always been the focus of clinicians due to its high incidence and high disability rate. Much progress has been made in understanding the injury mechanism, clinical features, MR images, and treatment options. Early prediction of the functional prognosis of patients is conducive to guiding followup treatment and giving the patients and their families a realistic idea of long-term expectations. Wilson ${ }^{[27]}$ and Kaminski et al. ${ }^{[11]}$ constructed linear regression models based on similar clinical features and MR images in 2012 and 2017, respectively. However, from the current point of view, their research has several small problems: 1) Wilson's study is a retrospective study, and some key data is missing; 2) the validity of the linear regression prediction model is limited; and 3) the influence of the treatment plan is not considered. Many clinical trials have shown that methylprednisolone ${ }^{[2,6]}$ and early surgery $[1,4,22,28]$ improve the prognosis of patients, and these measures have been included in the guidelines. As the most advanced technology in machine learning at present ${ }^{[30]}$, XGBoost has been widely used in various fields, such as industry, commerce and environmental protection, to construct nonlinear regression models. For the above reasons, we used XGBoost technology to incorporate representative data into the analysis to construct a nonlinear regression prediction model for the functional outcome of patients with acute SCI.

In the process of constructing the predictive model, we counted the importance of each feature's value in predicting the patient's functional outcome. AMS has been found to play the most important role in predicting the functional outcome of patients, while AIS is relatively less important. In previous studies, both AMS and AIS were considered to be related to the improvement of patients' neurological function ${ }^{[11,27]}$. We believe that there are broad differences in AMS in the same AIS grade. AIS is a hierarchical grading index, while AMS refers to the accumulation of key muscle group strength grading, which is a continuous variable ${ }^{[19]}$. The SCIM score is composed of 19 items with three main domains: self-care, respiration and sphincter management and mobility [8]. The realization of each function is closely related to the strength of key muscle groups, so AMS plays a more critical role in predicting functional outcome. This can also verify that AIS alone is less effective in judging the functional outcome of patients ${ }^{[10,29]}$.

We found that age also played an important role in predicting functional outcome. Age has always been considered to be significantly related to the improvement of patients' neurological function ${ }^{[17,18,26]}$. In Wilson's prediction model ${ }^{[27]}$, age was also included in the analysis as an important predictor. However, the surgical timing ranks last in importance, which suggests that the surgical timing may have a relatively low impact on the functional prognosis of patients with $\mathrm{SCl}$. This shows that the functional recovery after $\mathrm{SCl}$ is more closely related to the severity of the injury and the age of the patient, while the timing of surgery can only have a small impact. This research conclusion does not mean that early surgery is not 
beneficial to the improvement of patients' neurological function and does not conflict with previous clinical studies.

Through correlation analysis, we found that there was a significant correlation between AIS grade, BASIC score and AMS. When patients have combined injuries, such as combined fractures, pain, and brain injuries, it is very important to assess the severity of the patient's SCI through MR. The BASIC score was the first axial MR grading system proposed by Talbott in $2015^{[8]}$. Multiple clinical studies have proven that the BASIC score has a significant correlation with the severity of $\mathrm{SCl}$ and predicting functional improvement ${ }^{[7,15]}$. Our research also further supports the view that the higher the AIS grade is, the lower the severity of SCI is, the higher the AMS is, and the lower the BASIC score is.

\section{Limitations}

1) The sample size data were insufficient. This is one of the largest prospective studies about constructing a model for predicting the functional outcome of acute $\mathrm{SCl}$, but for machine learning, the sample size should be as large as possible. 2) The validation set data were collected retrospectively, while the model we built was based on a prospective study. 3) The constructed prediction model can only be stored in the form of an algorithm, which limits its promotion and extensive verification. 4) A small proportion of the clinical data were not collected within 72 hours.

\section{Conclusion}

We verified the feasibility of using XGBoost to construct a nonlinear regression prediction model for the functional outcome of patients with acute $\mathrm{SCl}$, and we found that age and AMS play the most important role in predicting the functional outcome. We also found a significant correlation between AIS at admission, baseline AMS and BASIC score. However, due to the limitations mentioned above, it is necessary to conduct more extensive and in-depth research.

\section{Declarations}

\section{Funding}

This study was funded by Ministry of Education Key Laboratory of trauma treatment and nerve regeneration.

\section{Conflicts of interest}

SZ.Z, BX.H, WY.X, F.X, DY.Z and BG.J declare that they have no conflicting interests

\section{Availability of data and material}

The datasets generated and analyzed during the current study are not publicly available due to the data also forms part of an ongoing study but are available from the corresponding author on reasonable 
request

\section{Code availability}

Concluded in the supplementary materials.

\section{Authors' contributions}

DY.Z and BG.J were responsible for the study design. SZ.Z, BX.H and WY.X contributed to the acquisition and analysis of data. BX.H, SZ.Z and F,X contributed to the interpretation and analysis of data. SZ.Z and WY.X were responsible for drafting the article. BX.H and F.X were responsible for revising it critically for important intellectual content. DY.Z and BG.J have approved the version to be published and all subsequent versions. SZ.Z, BX.H and WY.X were major contributors and should be listed as to co-first authors.

\section{Ethics approval}

The study was approved by the ethics committee of Peking University People's Hospital, approval number: 2016PHB136-01.

\section{Consent to participate}

All patients had the contents of the study fully explained and signed the informed consent form before enrollment.

\section{Consent for publication}

Not Applicable

\section{References}

1. Badhiwala JH, Wilson JR, Witiw CD, Harrop JS, Vaccaro AR, Aarabi B, Grossman RG, Geisler FH, Fehlings MG (2021) The influence of timing of surgical decompression for acute spinal cord injury: a pooled analysis of individual patient data. Lancet Neurol 20(2):117-126. doi:10.1016/s14744422(20)30406-3

2. Bracken MB, Shepard MJ, Holford TR, Leo-Summers L, Aldrich EF, Fazl M, Fehlings M, Herr DL, Hitchon PW, Marshall LF, Nockels RP, Pascale V, Perot PL Jr, Piepmeier J, Sonntag VK, Wagner F, Wilberger JE, Winn HR, Young W (1997) Administration of methylprednisolone for 24 or 48 hours or tirilazad mesylate for 48 hours in the treatment of acute spinal cord injury. Results of the Third National Acute Spinal Cord Injury Randomized Controlled Trial. National Acute Spinal Cord Injury Study. Jama 277(20):1597-1604

3. Catz A, Itzkovich M, Agranov E, Ring H, Tamir A (1997) SCIM-spinal cord independence measure: a new disability scale for patients with spinal cord lesions. Spinal cord 35(12):850-856. 
doi:10.1038/sj.sc.3100504

4. Fehlings MG, Tetreault LA, Wilson JR, Aarabi B, Anderson P, Arnold PM, Brodke DS, Burns AS, Chiba K, Dettori JR, Furlan JC, Hawryluk G, Holly LT, Howley S, Jeji T, Kalsi-Ryan S, Kotter M, Kurpad S, Marino RJ, Martin AR, Massicotte E, Merli G, Middleton JW, Nakashima H, Nagoshi N, Palmieri K, Singh A, Skelly AC, Tsai EC, Vaccaro A, Yee A, Harrop JS (2017) A Clinical Practice Guideline for the Management of Patients With Acute Spinal Cord Injury and Central Cord Syndrome:

Recommendations on the Timing ( $\leq 24$ Hours Versus $>24$ Hours) of Decompressive Surgery. Global spine journal 7(3 Suppl):195s-202s. doi:10.1177/2192568217706367

5. Fehlings MG, Vaccaro A, Wilson JR, Singh A, Harrop DWC, Aarabi JS, Shaffrey B, Dvorak C, Fisher M, Arnold C, Massicotte P, Lewis EM, Rampersaud S R (2012) Early versus delayed decompression for traumatic cervical spinal cord injury: results of the Surgical Timing in Acute Spinal Cord Injury Study (STASCIS). PloS one 7(2):e32037. doi:10.1371/journal.pone.0032037

6. Fehlings MG, Wilson JR, Harrop JS, Kwon BK, Tetreault LA, Arnold PM, Singh JM, Hawryluk G, Dettori JR (2017) Efficacy and Safety of Methylprednisolone Sodium Succinate in Acute Spinal Cord Injury: A Systematic Review. Global spine journal 7(3 Suppl):116s-137s. doi:10.1177/2192568217706366

7. Haefeli J, Mabray MC, Whetstone WD, Dhall SS, Pan JZ, Upadhyayula P, Manley GT, Bresnahan JC, Beattie MS, Ferguson AR, Talbott JF (2017) Multivariate Analysis of MRI Biomarkers for Predicting Neurologic Impairment in Cervical Spinal Cord Injury. AJNR American journal of neuroradiology 38(3):648-655. doi:10.3174/ajnr.A5021

8. Itzkovich M, Gelernter I, Biering-Sorensen F, Weeks C, Laramee MT, Craven BC, Tonack M, Hitzig SL, Glaser E, Zeilig G, Aito S, Scivoletto G, Mecci M, Chadwick RJ, El Masry WS, Osman A, Glass CA, Silva P, Soni BM, Gardner BP, Savic G, Bergström EM, Bluvshtein V, Ronen J, Catz A (2007) The Spinal Cord Independence Measure (SCIM) version III: reliability and validity in a multi-center international study. Disabil Rehabil 29(24):1926-1933. doi:10.1080/09638280601046302

9. Jazayeri SB, Beygi S, Shokraneh F, Hagen EM, Rahimi-Movaghar V (2015) Incidence of traumatic spinal cord injury worldwide: a systematic review. European spine journal: official publication of the European Spine Society, the European Spinal Deformity Society, and the European Section of the Cervical. Spine Research Society 24(5):905-918. doi:10.1007/s00586-014-3424-6

10. Kalsi-Ryan S, Wilson J, Yang JM, Fehlings MG (2014) Neurological grading in traumatic spinal cord injury. World neurosurgery 82(3-4):509-518. doi:10.1016/j.wneu.2013.01.007

11. Kaminski L, Cordemans V, Cernat E, M'Bra KI, Mac-Thiong JM (2017) Functional Outcome Prediction after Traumatic Spinal Cord Injury Based on Acute Clinical Factors. J Neurotrauma 34(12):20272033. doi:10.1089/neu.2016.4955

12. Kriz J, Kulakovska M, Davidova H, Silova M, Kobesova A (2017) Incidence of acute spinal cord injury in the Czech Republic: a prospective epidemiological study 2006-2015. Spinal cord 55(9):870-874. doi:10.1038/sc.2017.20

13. Kumar R, Lim J, Mekary RA, Rattani A, Dewan MC, Sharif SY, Osorio-Fonseca E, Park KB (2018) Traumatic Spinal Injury: Global Epidemiology and Worldwide Volume. World neurosurgery 
113:e345-e363. doi:10.1016/j.wneu.2018.02.033

14. Li Y, Li M, Li C, Liu Z (2020) Forest aboveground biomass estimation using Landsat 8 and Sentinel$1 \mathrm{~A}$ data with machine learning algorithms. Scientific reports 10(1):9952. doi:10.1038/s41598-02067024-3

15. Mabray MC, Talbott JF, Whetstone WD, Dhall SS, Phillips DB, Pan JZ, Manley GT, Bresnahan JC, Beattie MS, Haefeli J, Ferguson AR (2016) Multidimensional Analysis of Magnetic Resonance Imaging Predicts Early Impairment in Thoracic and Thoracolumbar Spinal Cord Injury. J Neurotrauma 33(10):954-962. doi:10.1089/neu.2015.4093

16. Middleton JW, Harvey LA, Batty J, Cameron I, Quirk R, Winstanley J (2006) Five additional mobility and locomotor items to improve responsiveness of the FIM in wheelchair-dependent individuals with spinal cord injury. Spinal cord 44(8):495-504. doi:10.1038/sj.sc.3101872

17. Oleson CV, Marino RJ, Leiby BE, Ditunno JF (2016) Influence of Age Alone, and Age Combined With Pinprick, on Recovery of Walking Function in Motor Complete, Sensory Incomplete Spinal Cord Injury. Arch Phys Med Rehabil 97(10):1635-1641. doi:10.1016/j.apmr.2016.01.024

18. Penrod LE, Hegde SK, Ditunno JF Jr (1990) Age effect on prognosis for functional recovery in acute, traumatic central cord syndrome. Arch Phys Med Rehabil 71(12):963-968

19. Roberts TT, Leonard GR, Cepela DJ (2017) Classifications In Brief: American Spinal Injury Association (ASIA) Impairment Scale. Clin Orthop Relat Res 475(5):1499-1504. doi:10.1007/s11999-016-5133-4

20. Singh H, Shah M, Flett HM, Craven BC, Verrier MC, Musselman KE (2018) Perspectives of individuals with sub-acute spinal cord injury after personalized adapted locomotor training. Disabil Rehabil 40(7):820-828. doi:10.1080/09638288.2016.1277395

21. Talbott JF, Whetstone WD, Readdy WJ, Ferguson AR, Bresnahan JC, Saigal R, Hawryluk GW, Beattie MS, Mabray MC, Pan JZ, Manley GT, Dhall SS (2015) The Brain and Spinal Injury Center score: a novel, simple, and reproducible method for assessing the severity of acute cervical spinal cord injury with axial T2-weighted MRI findings. Journal of neurosurgery Spine 23(4):495-504. doi:10.3171/2015.1.Spine141033

22. Tanaka C, Tagami T, Kaneko J, Fukuda R, Nakayama F, Sato S, Takehara A, Kudo S, Kuno M, Kondo M, Unemoto K (2019) Early versus late surgery after cervical spinal cord injury: a Japanese nationwide trauma database study. J Orthop Surg Res 14(1):302. doi:10.1186/s13018-019-1341-4

23. Torlay L, Perrone-Bertolotti M, Thomas E, Baciu MJBI (2017) Machine learning-XGBoost analysis of language networks to classify patients with epilepsy

24. van den Berg ME, Castellote JM, de Pedro-Cuesta J, Mahillo-Fernandez I (2010) Survival after spinal cord injury: a systematic review. J Neurotrauma 27(8):1517-1528. doi:10.1089/neu.2009.1138

25. Wang T, Jiang B (2019) Road traffic mortality in China: good prospect and arduous undertaking. The Lancet Public health 4(5):e214-e215. doi:10.1016/s2468-2667(19)30063-5

26. Wilson JR, Davis AM, Kulkarni AV, Kiss A, Frankowski RF, Grossman RG, Fehlings MG (2014) Defining age-related differences in outcome after traumatic spinal cord injury: analysis of a combined, 
multicenter dataset. The spine journal: official journal of the North American Spine Society 14(7):1192-1198. doi:10.1016/j.spinee.2013.08.005

27. Wilson JR, Grossman RG, Frankowski RF, Kiss A, Davis AM, Kulkarni AV, Harrop JS, Aarabi B, Vaccaro A, Tator CH, Dvorak M, Shaffrey Cl, Harkema S, Guest JD, Fehlings MG (2012) A clinical prediction model for long-term functional outcome after traumatic spinal cord injury based on acute clinical and imaging factors. J Neurotrauma 29(13):2263-2271. doi:10.1089/neu.2012.2417

28. Wilson JR, Witiw CD, Badhiwala J, Kwon BK, Fehlings MG, Harrop JS (2020) Early Surgery for Traumatic Spinal Cord Injury: Where Are We Now? Global spine journal 10 (1 Suppl):84s-91s. doi:10.1177/2192568219877860

29. Wutte C, Becker J, Klein B, Mach O, Panzer S, Stuby FM, Strowitzki M, Maier D, Thomé C, Grassner L (2020) Early Decompression (< 8 Hours) Improves Functional Bladder Outcome and Mobility After Traumatic Thoracic Spinal Cord Injury. World neurosurgery 134:e847-e854. doi:10.1016/j.wneu.2019.11.015

30. XGBoost: A Scalable Tree Boosting System. In: the 22nd ACM SIGKDD International Conference, 2016

\section{Tables}

Table 1: Predictor and outcome variables

Abbreviation: GM, grey matter; WM, white matter.

Table 2: Population Characteristics

\begin{tabular}{ll} 
Age & $50.45 \pm 14.91$ \\
\hline Sex & Male $=182 ;$ Female $=67$ \\
\hline Level of injury & Cervical $=193 ;$ Thoracic $=56$ \\
\hline AIS at admission & $A=59 ; B=13 ; C=50 ; D=127$ \\
\hline Baseline AMS & $63.51 \pm 28.60$ \\
\hline BASIC score & Score $1=134 ;$ Score $2=60 ;$ Score $3=29 ;$ Score $4=26$ \\
\hline Time to operation & Early surgery $=89 ;$ Delayed surgery $=160$ \\
\hline SCIM score & $80.90 \pm 22.75$
\end{tabular}

\section{Figures}




\section{Variables Description}

\section{A. Predictor variabels}

Age Continuous;

Level of Cervical; Thoracic

injury

AlS at $\quad$ Grade $A=1$ : no motor or sensory function is preserved in the sacral segments

admission Grade $B=2$ : sensory but no motor function is preserved below the neurological level and includes the sacral segments

Grade $\mathrm{C}=3$ : motor function is preserved below the neurological level, and more than half of key muscles below this level have a muscle grade less than 3

Grade $D=4$ : motor function is preserved below the neurological level, and more than half of key muscles below this level have a muscle grade of 3 or more

Baseline Continuous; Rang: 0-100

AMS

BASIC score $\quad 0=$ normal; $1=\mathrm{GM}$ only $; 2=$ some $\mathrm{WM} ; 3=$ all $\mathrm{WM}$ in plane; $4=$ with hemorrhage

Time to Eraly surgery ( $=<24$ hours); Delayed surgery ( $>24$ hours)

operation

\section{B. Outcome variables}

SCIM III

Self care

1. Feeding

2. Bathing
A. Upper body
B. Lower body
$/ 3$
3. Dressing
A. Upper body
B. Lower body
4. Grooming
$/ 3$
14
$/ 4$
13

/3

5. Respiration

Respiration

and

6. Sphincter management - bladder

7. Sphincter management - bowel

8. Use of toilet

$/ 10$

9. Mobility in bed and action to prevent pressure sores

10. Transfers: bed-wheelchair

Mobility

11. Transfers: wheelchair-toilet-tub

12

(room and

toilet)

Mobility

12. Mobility indoors

18

(indoors and

13. Mobility for moderate distances (10-100 meters)

outdoors)

14. Mobility outdoors (more than 100 meters)

15. Stair management

16. Transfers: wheelchair-car

17. Transfers: ground-wheelchair

$13^{/ 2} / 2^{18}$




\section{Comparison between predicted value and actual value}

120

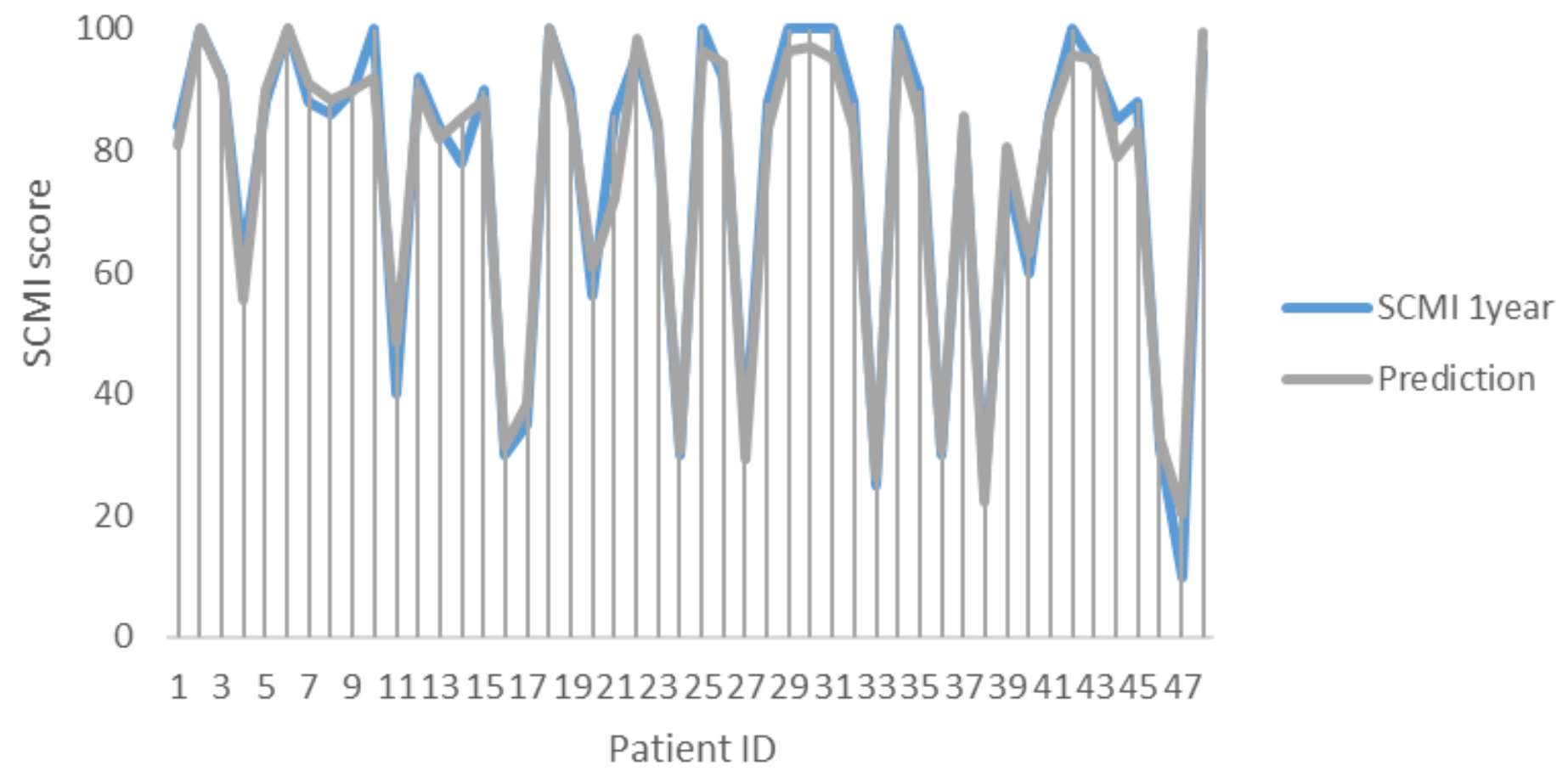

Figure 1

Validation of predictive model. Comparison between predicted value and actual value. 


\section{Features importance}

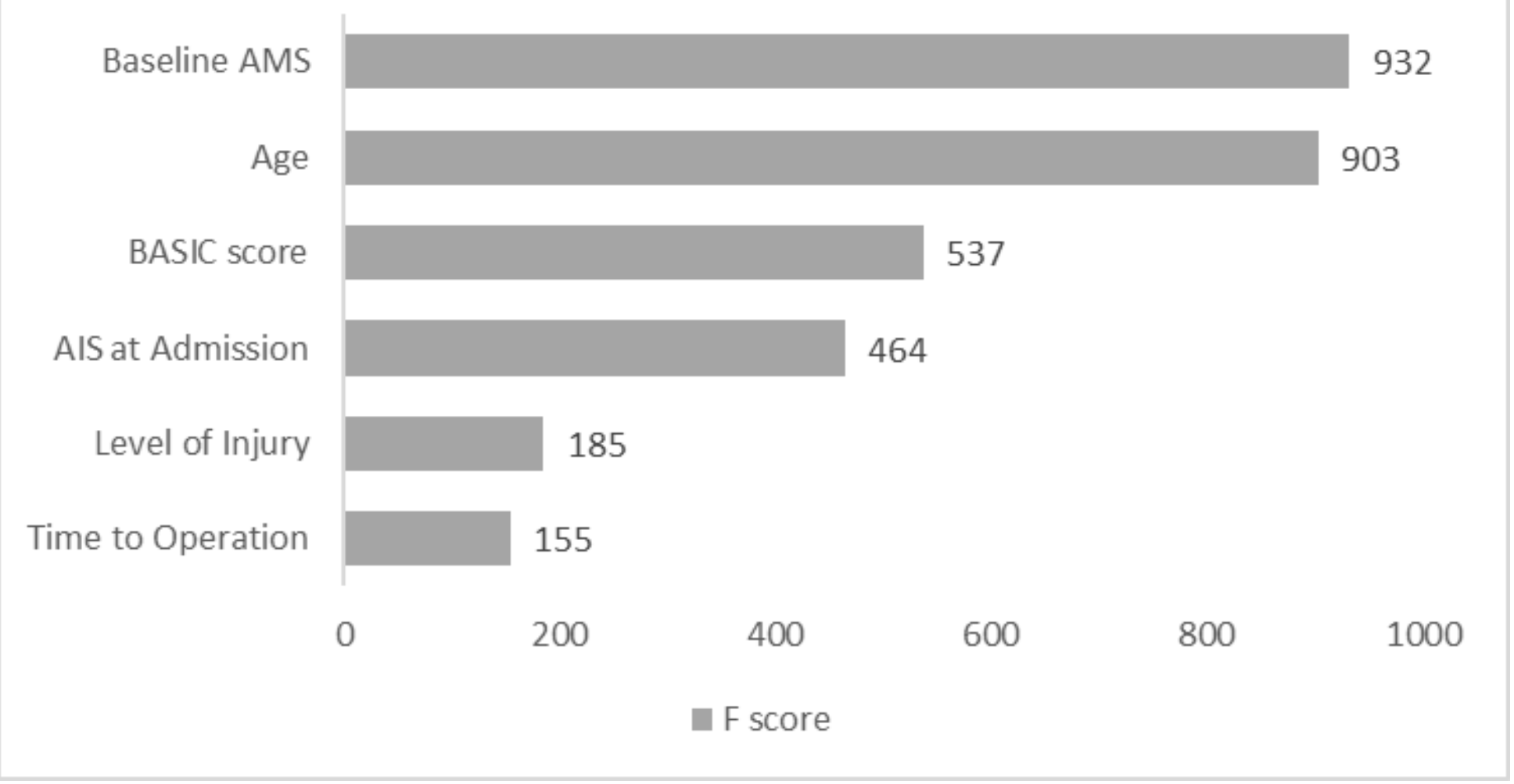

Figure 2

Rank of features importance. 


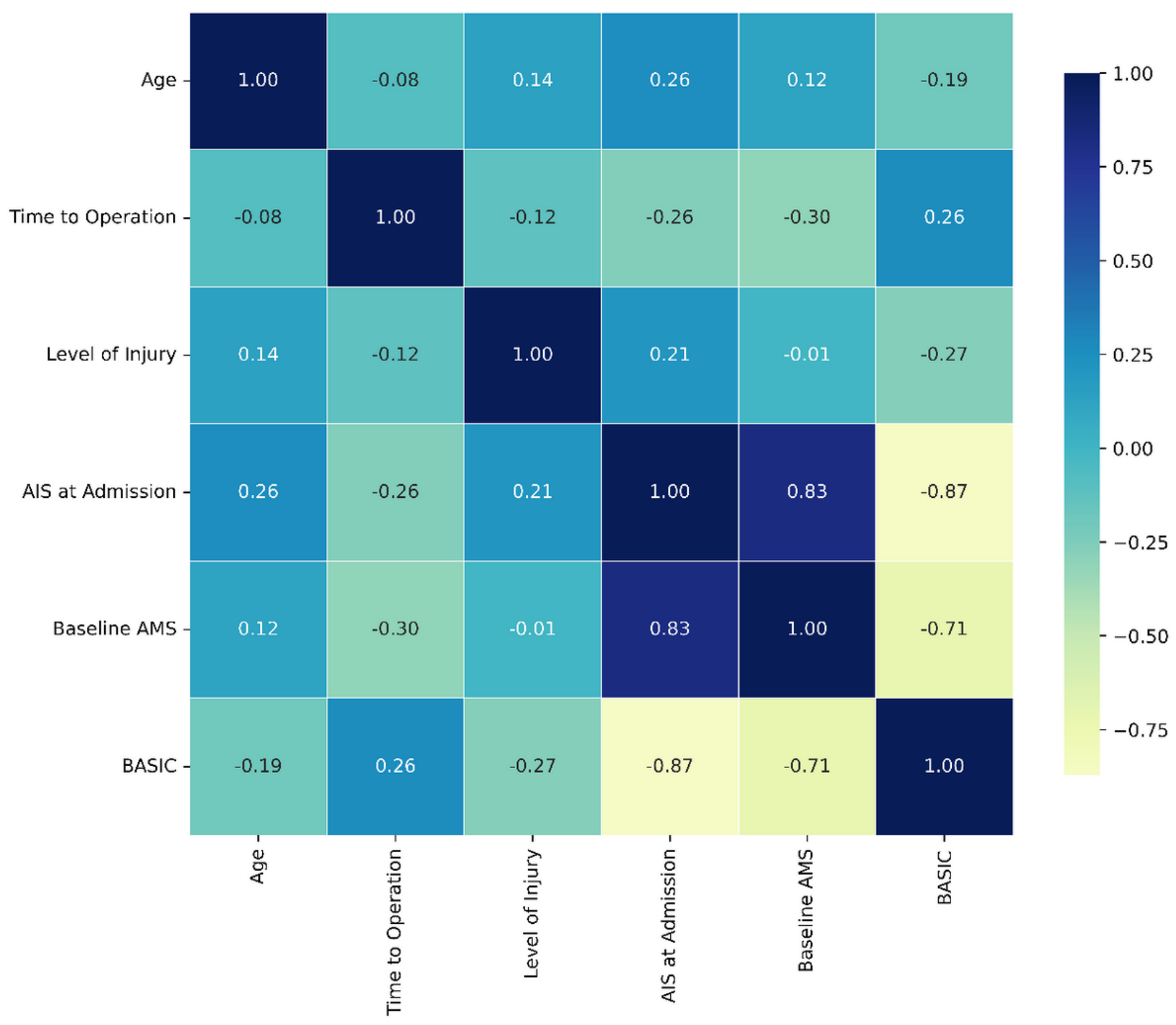

Figure 3

Correlation of the 6 predictors.

\section{Supplementary Files}

This is a list of supplementary files associated with this preprint. Click to download.

- SupplementaryMaterial1.docx

- SupplementaryMaterial2.docx

- SupplementaryMaterial3.docx

- SupplementaryMaterial4.ipynb 